\title{
Collective Action and Cultural Change: Revisiting Eisenstadt's Evolutionary Theory
}

\author{
Seth Abrutyn \\ University of British Columbia \\ Justin Van Ness \\ Marshall Taylor \\ University of Notre Dame
}

Published in Journal of Classical Sociology

\begin{abstract}
Eisenstadt's most well-known contributions come primarily from his research on "multiple modernities." Less appreciated has been his evolutionary theory of cultural change. In this article, we revisit Eisenstadt's evolutionary theory in order to make explicit his potential contributions to the neoevolutionary tradition and demonstrate where his contribution can be further appreciated. In short, Eisenstadt's theory supplements macro-level materialist and micro-level bio-psychological theories by (1) offering a group-level theory that takes agency and historicity seriously by calling attention to the role of institutional entrepreneurs and their projects for cultural change, (2) formulating a multi-linear, multi-directional theory of evolution that avoids determinist traps, (3) highlighting non-materialist crises such as the widespread breakdown in trust, the discontents of centralized and consolidated power, and the collapse of a shared sense of meaning, and (4) accounting for the possible conditions of success or failure. Historical examples are used to illustrate Eisenstadt's model.
\end{abstract}

Keywords: Eisenstadt; sociocultural evolution; entrepreneurs; institutions; historical-comparative sociology

Word Count: 12, 461 


\section{INTRODUCTION}

Though only a few years since S.N. Eisenstadt's passing, we believe an assessment of his contribution to the discipline continues to be a worthwhile project. Eisenstadt's work, spanning several decades, is formidable in many respects. Primarily, it was his later interests (e.g., 1986, 2000; Eisenstadt et al. 1987), what he termed "multiple modernities," that has deservingly received much attention (Alexander and Colomy 1990; Alexander 1992; Wittrock 2005; Joas 2012). In the paper, we argue that his earliest work on sociocultural evolution $(1963,1964,1965,1971)$ deserves a renewed focus, especially in light of the recent advances made in neo-evolutionary theory (Machalek and Martin 2016) and the growing integration of cognitive and evolutionary psychology into sociology (Norenzayan 2013; Slingerland et al. 2013). To our knowledge, evolutionary sociologists have mostly ignored or are unaware of Eisenstadt's evolutionary scholarship (Turner 2003; Richerson and Boyd 2005; Runciman 2009; Richerson and Christiansen 2013), and thus, bringing him into explicit dialogue with recent contributions may provide fruitful extensions of both Eisenstadt's own theory and the various strands of neo-evolutionary social science.

Since Wilson's (1975) tome on sociobiology, evolutionary sociology has rapidly evolved far beyond the stage models of 1960s sociology (Bellah 1964; Lenski 1966; Parsons 1966). As Marion Blute (2010) notes, biologists differentiate between developmentalism and evolution, and thus, so should sociologists insofar as stage models are developmental theories. Another approach, which Turner has advocated (Turner 2003, 2010b; Abrutyn and Lawrence 2010), is for sociology to return to selection pressures and the processes of selection so as to best incorporate evolutionary principles. Indeed, this strategy has become the standard as neo-Darwinian theorizing has emerged alongside various other neo-evolutionary theories like gene-culture interaction (Lenski 2005; Richerson and Boyd 2005), crossspecies studies (Maryanski and Ishii-Kuntz 1991), and neurosociology (Franks and Turner 2013). Though these studies have done much to rescue evolution from the older nineteenth century tendencies 
towards developmental progressivism (Sanderson 2007), they tend to focus only on general evolution (Sahlins 1960) while ignoring the details on the ground, or the historically and socioculturally contingent forces that play a role in shaping specific cases (Boyd and Richerson 1992). And, while Eisenstadt moved away from evolutionism as the 1970s progressed, we believe not only does his theorizing improve upon neo-evolutionary work today but, conversely, neo-evolutionary work can speak directly to the spirit of his scholarly goals in the 1960 s - that is, to challenge the Parsons (1966)/Bellah (1964) progressivist evolutionism, while giving teeth to a cultural perspective that supplements Lenski's (1966) overly materialist (subsistence technology) stage model.

In short, then, by focusing on Eisenstadt's updated version of Weber's (1946a) charismatic carrier groups, or what Eisenstadt called institutional entrepreneurs, these fine-grained details can be brought into alignment with a general theory of group-level selection (Abrutyn 2014b; Abrutyn and Van Ness 2015) without having to resort to ad hoc adaptionalism, stage models, or other vague "unfolding" processes. Moreover, by considering the role of institutional entrepreneurs amidst historical and sociocultural context, we can provide "teeth" to Turner's $(2010,2012)$ argument that sociology embrace Durkheimian, Spencerian, and Marxian selection as distinct from Darwinian selection (Abrutyn 2014a, 2015a), without doing violence to the selection-levels which are still shaped by conventional Darwinian patterns. Indeed, Eisenstadt's evolutionary theory-as a conscious break from Parsons' (1966) and Bellah's (1964) blind, unilinear, unidirectional models - can offer concepts and processes that build the scaffolding necessary for understanding why, how, and when evolution works on the group-level (Wilson 2001, 2002); its outcome is unpredictable because of the interests of competing collectives as well as the growing existential discontent produced by ever-larger societies and institutional mechanisms of control that grew further and further away from the local, and heterogeneity that generates nearly limitless alternative societies.

Taking all of this together, our primary goal in this paper can be understood as follows: to 
synthesize Eisenstadt's evolutionary work, in order to elucidate concepts which we believe are particularly useful for a modern cultural approach to neo-evolutionary theory, and, in order to facilitate this contribution, we engage in a translation of Eisenstadt's concepts with the terminology of more recent neo-evolutionary theorizing. In the following section, we attend to some basic definitional and conceptual work in Eisenstadt's theory. First, we address the implicit question of "what evolves" in Eisenstadt's theorizing. Following this, we discuss how Eisenstadt's institutional spheres-i.e., macrostructural and cultural "sites" of social organization-offer a means of understanding sociocultural evolution as the qualitative transformation of societal configurations. Finally, we outline the role of frameworks, autonomy, and institutional centers in this transformative process. This definitional and conceptual work is necessary for a more robust understanding of the subsequent section, which addresses the role and importance of meso-level institutional entrepreneurs in evolutionary processes and dynamics. As we delineate the processes and dynamics, historical examples will be drawn from in similar style as Eisenstadt's own work. Though the systematic treatment of a single case would, perhaps, offer as effective of a method, it is the generalizability that we prefer to focus on.

\section{FUNDAMENTAL BUILDING BLOCKS}

\section{Polity, Religion, and the Question of What Evolves}

Though Eisenstadt was never crystal clear in positing a single theory of evolution we can look at two clues to best understand what he thought evolved. First, the bulk of Eisenstadt's historical research was focused on two specific epochs and processes: the evolution of political autonomy in agrarian states beginning some 5,000 years ago (Eisenstadt 1963, 1977; Eisenstadt et al. 1987) and the emergence of religious entrepreneurs $(1980,1982,1986,1990)$ during the so-called Axial Age (c. $800-200) .{ }^{1}$ Abrutyn (2014a) has argued that in both sets of cases, we find historical processes facilitating the emergence of

\footnotetext{
${ }^{1}$ The latter epoch is noticeably different from the former in that Eisenstadt had already begun to abandon evolutionary concepts when examining the religious changes that occurred in the first millennium BCE.
} 
specialized collectives (i.e., political and religious entrepreneurs), their pursuit of structural and symbolic independence, and their effort to reconfigure the physical, temporal, social, and symbolic space of society. Generally, each case presents a crisis or set of crises that "frees" one or more sets of entrepreneurs from the constraints of extant normative, symbolic, and organizational frameworks and gives these actors some "breathing room" to invent new frameworks and pursue their institutionalization (Colomy 1998). ${ }^{2}$ In the end, what we find are qualitatively transformed institutional systems: one or more institutional spheres (e.g., polity, religion) with greater autonomy (Eisenstadt $1977,1987) ;$ a reshaped, differentiated institutional landscape with new role-status positions and organizational units (Eisenstadt 1986, 2012); and, on a phenomenological level, new collective goals superimposed on self-interested goals (Eisenstadt 1971, 1982). Or, put differently, Eisenstadt's implicit model considered the consequences of evolution across all three principal levels of analysis: macro, meso, and micro. From this briefest of explications, we can sketch out a working framework of what evolves.

\section{Institutional Spheres}

The concept "institution" has long been used to mean anything that endures for some indefinite period of time and appears to the actors as eternal (Jepperson 1991). A more narrow usage of the term has been employed by evolutionary-institutionalists (Turner 2003, 2010; Nolan and Lenski 2010; Abrutyn 2014b): macro-level structural and cultural frameworks organized by and around one or more universal human concerns and constituted by individuals, collectives, and clusters of collectives (e.g., niches, fields) whose position is relative to the spaces associated with producing and distributing (tangible and intangible) resources linked to the concerns. There are several ubiquitous institutional spheres (Turner 2003) - kinship, polity, religion, law, economy - and many spheres which have more recently become

\footnotetext{
${ }^{2}$ Social movement researchers, particularly those in the political process tradition, have explicitly focused attention on such openings as "structural opportunities" (McAdam 1999; Meyer and Minkoff 2004; Goodwin 2001). Others have emphasized that the most important factor of these openings depends on the perception of an opportunity rather than objective conditions (e.g., Kurzman 1996; Summers-Effler 2002).
} 
autonomous and, therefore, discrete structural and cultural milieus inhabited by individuals and collectives-e.g., science, medicine, art, sport (Abrutyn 2014b).

Institutional spheres are group-level "survivor machines" (Maryanski and Turner 1992:2). ${ }^{3}$ They

are enduring in a number of ways. First, they are the hidden source of social control and coordination which facilitate and constrain self-interested action, impose divisions of labor that harness collective power, and obfuscate inequities and domination. Second, they are the source of patterns of action, labels for emotions and feeling rules guiding expression, ideologies and vocabularies of motives for developing attitudes and appraisals, and procedures for making decisions for large swaths of the population. Finally, they are the material and symbolic storehouses of collective memories-both "official" elite memories and the material from which local memories are constructed-that provide actors with a sense of shared coherent reality, even when that reality, on the ground, varies tremendously. In short, institutional spheres are the mechanisms by which societies regulate and integrate actors, while providing the underlying source(s) of legitimation for society. For Eisenstadt (1971), institutional spheres are the domains of societal evolution. It is at the institutional level that patterns of action, decision-making, goal setting, and collective power can be restructured and "taken for granted" by actors operating within those spheres' realms of influence.

\footnotetext{
${ }^{3}$ We begin by considering some of the major building blocks of Eisenstadt's model with a brief, but necessary, aside on concepts. On the one hand, a re-examination of a scholar's work should be articulated on his or her terms. On the other hand, much of the terminology Eisenstadt drew from is currently out of use and/or draws us back into debates surrounding functionalist models of social change. Rather than wade into the morass of these debates - terrain which has been more than tread upon for decades now-we look to fresh concepts that mirror Eisenstadt's thinking without losing the generalizable insights; moreover, by subtly shifting our vocabularies, Eisenstadt's work is more easily grafted onto extant neo-evolutionary thought. For example, Eisenstadt's work grew out of the Parsonsian system logic, where subsystems like polity, economy, and culture (e.g., religion) were the dominant macro structural phenomena (Parsons and Smelser 1956). While neo-system's theory has worked to rehabilitate the weaknesses of Parsons' systems models (Luhmann 1995), these models are ahistorical and not very useful empirically. Returning to the classics, Jonathan Turner $(2003,2010)$ has supplanted systems with institutional domains, or macro-social spaces like polity or religion that do not fit into a four-fold functionalist model; rather, they emerge from ethnographic, historical, and archaeological evidence (Nolan and Lenski 2010). Additionally, switching out the master functionalist process of differentiation with that of autonomy, which Abrutyn $(2009,2014 b)$ has argued allows for a stronger cultural theory that considers culture independently of (yet interrelated to) structure opens the theory up to a whole host of advances such as those found in the institutional logics perspective (Thornton et al. 2012).
} 
Eisenstadt, like most functionalists (Parsons 1966; Luhmann 2012), saw the general pattern of sociocultural evolution as increasing population growth and density, differentiation as a means of resolving this growth and density, and, consequently, problems of integration and regulation that further required new solutions. To be sure, functionalists are not the only evolutionary thinkers to recognize this general social historical pattern of iterative growth, problem emergence/intensification, attempted problem-solving, and complexification (Tilly 1990; Chirot 1994; Chase-Dunn and Hall 1997; Abrutyn and Lawrence 2010). Even Weber (1946b) argued that macro social orders like polity and economy became highly bounded rationalized spaces whose boundaries were protected like "jealous gods" protect their people's purity.

Clearly, Eisenstadt felt there was something "adaptive" about institutional spheres, but we do not feel this is a necessary path to traverse; in part because importing biological evolutionary metaphors has its limits at some levels of sociocultural reality (Turner and Maryanski 2008; Runciman 2009). That is, it's enough to say institutional spheres are survivor machines in so far as they (1) allow cultural systems that appear coherent and provide actors with meanings that motivate them to live and do the things they should to persist over time, (2) give actors a shared sense of history and destiny that becomes the underlying basis for solidarious rituals, occasional collective effervescence, and an insider/outsider status, and (3) produce real or imagined stability for an indefinite number of generations in terms of resource production and distribution (even where inequitable and maladaptive for some proportion of the population), power relations, and patterns of daily existence.

Evolution, then, is not a process of adaptation at the institutional level of social reality, but rather the qualitative transformation of cultural systems and structural reality so that physical, temporal, social, and symbolic spaces are radically changed and, on a phenomenological level, everyday reality-for a significant portion of the population-is reconstructed (Abrutyn 2013b, 2015a). For the biological sciences, evolution is premised on environmental changes generating natural selection that 
works on the frequency of phenotypic expression in a given population (Mayr 2001). In the social sciences, while some have pushed solely for a neo-Darwinian model that emphasizes "memes" or, more recently, modules in the brain (for a review, see Blute 2010), sociocultural evolution at a more macro scale has been distinguished from other types of social change in terms of quantitative growth versus qualitative change (Abrutyn and Lawrence 2010). Directly connected to qualitative change is the emphasis on selection, which unlike the biotic world, involves purposive, concerted efforts (Verkamp 1991; Turner 2003; Runciman 2009; Abrutyn 2013b). Institutions become the warehouses or libraries that come to store the technological, organizational, and symbolic changes that qualitatively transform societies physically, temporally, socially, and symbolically. Mesopotamia and Egypt in the mid-fourth millennium BCE were not simply quantitatively different from the chiefdoms that preceded them or coexisted uneasily beside them; Eisenstadt recognized they were qualitatively different at the macro-level as polity grew discrete from kinship and came to penetrate and dominate local levels of kin organization (Yoffee 2005), as well as on the meso-level with the emergence of new organizational (bureaucracies; priesthoods; warrior castes) divisions of labor (Adams 1966; Flannery 1972) and the micro-level as political attitudes, actions, goals, and rules phenomenologically reoriented a significant swath of people's everyday reality (Abrutyn 2013a). At the macro level of social reality, adaptation is not the primary "reason" or outcome but the complete transformation of human societies.

\section{Frameworks, Autonomy, Centers}

If institutional spheres are what evolve, can we identify some major processes that clue us in to evolution? That is to say, since institutional spheres are not in and of themselves "observable," to what indicators can we turn to measure their presence, significance, and efficacy in social and cultural tranformation? For one thing, Colomy (1998) has argued Eisenstadt's entrepreneurs worked to construct and crystallize new normative, symbolic, and organizational frameworks while concomitantly 
casting doubt on existing frameworks as unjust, immoral, and/or inefficient. ${ }^{4}$ In a sense, institutional spheres are external "warehouses" composed of overlapping symbolic and structural frameworks that provide actors with schemas for perception and action, and the means to internalize these schemas (Vaisey 2009). At the most basic level, then, sociocultural evolution is the selection process by which new frameworks are invented, crystallized, and institutionalized into macro-level structural and cultural milieu in ways that transform the everyday reality of a significant proportion of the population.

However, it is not just the frameworks that constitute evolution, according to Eisenstadt the level of "complexity" found within institutional spheres matters too.

Early on, Eisenstadt used the term differentiation to talk about complexity, but as he transitioned away from evolutionism into the Axial Age, he increasingly abandoned the process in favor of institutional autonomy (cf. 1986, 1990, 2012); more recently, Abrutyn (2009, 2014b) brought Eisenstadt into dialogue with Luhmann's (2012) usage of autonomy to underscore the process driving institutional domains to become more or less discrete structural and cultural milieus. The greater the degree of autonomy, the greater the degree to which (1) they are realized in physical and temporal space; (2) individuals, collectives, and clusters of collectives and, importantly, the relationships between them are distinguishable objectively and reflexively from other types of role-status positions or collectives; (3) the symbolic reality, constituted by specialized language, institutional logics, collective memory and identity, is set apart from other symbolic realities and, therefore, makes doing polity or religion phenomenologically different from doing kinship or economy. Thus, sociocultural evolution is, in part, a process of either creating more autonomy or, conversely, reducing the level of autonomy found in one or more institutional spheres and the subsequent effects one institution's autonomy, or sudden

\footnotetext{
${ }^{4}$ While Eisenstadt used the term "premises" in place of frameworks, by, once again, subtly shifting our language we can draw direct connections with Colomy's work on entrepreneurship as well as bring his work into dialogue with a rich social movements literature that has co-opted Goffman's "frame" metaphor in talking about how movements articulate their projects (Snow et al. 1986; Benford and Snow 2000; McVeigh, Myers, and Sikkink 2004).
} 
lack thereof, has on other institutional spheres.

We especially see this in the political cases Eisenstadt was interested in, where, for example, political goals became discrete from "goals of other spheres or groups in society" in that their "formation, pursuit, and implementation became largely independent of other groups, and were governed mostly by political criteria and by consideration of political exigency" (1963:19). The Axial Age, similarly, was a period in which the "common denominator of [the various religious cases] was their transformation into relatively autonomous spheres of society, regulated by autonomous criteria" (Eisenstadt 2012:279). Again, autonomy, for Eisenstadt, meant qualitative transformation at the macro, meso, and micro levels of social reality; and, though Eisenstadt never explicitly conceptualized it this way, the process of autonomy-and therefore sociocultural evolution-may also include the loss of autonomy (or, what others might call dedifferentiation (Rueschemeyer 1977) or "retrogression") as just as important as the emergence of greater and greater levels of autonomy (Abrutyn 2009).

One of the defining features of autonomy is the construction and preservation of an institutional center. For Edward Shils (1975), the center of society was the locus of the central (a) value system, (b) institutions, and (c) system of authority. It was, in short, the physical and cognitive source of "gravity" that drew the attention of the masses, and made a large, impersonal society like a nation-state possible. We can easily adjust this over-functionalized ecology, and argue instead that each autonomous institutional sphere has one or more centers. Some centers are physical spaces as big as Jerusalem (religion) or New York (economy) or as small as palaces or temples in agrarian states (Joyce 2000) and chiefs' huts in horticultural societies (Earle 1991). All centers, however, are cognitive in that the greater the level of autonomy, the greater is the degree to which a center penetrates the everyday reality of individual actors, and, thereby, the more internalized the center becomes in the cognitive schema carried by each actor. It does not mean the role-identity associated with a given center is always salient or prominent in the individual's identity hierarchy, or in every situation; it means that the person is 
oriented to the center and the appropriate role-identity (and the various meanings attributed to the identity and institutional sphere) can be activated in certain settings. The cognitive internalization of centers also implies a degree of taken-for-grantedness in that the polity and its autonomy, for instance, comes to be understood as "normal" and alternative institutional arrangements become more difficult to imagine. ${ }^{5}$ Institutional centers, then, are cognitively causal not only in the deliberate and discursive sense-but also at the pre-conscious, schematic, "extra-deliberative" level which motivates judgments and action below discursive awareness (Smith and DeCoster 2000; Vaisey 2009; Summers-Effler et al. 2014).

Yoffee's (2005:17) examination of textual and archaeological evidence in Mesopotamia confirms Eisenstadt's conclusions, as well as our slightly modified version of Eisenstadt: "The emergence of a political center [occurred via] a generalized structure of authority [which made its actors] distinct from kinship, priestly, or other hierarchies" (see also Adams 1966; Flannery 1972; Abrutyn 2013a). Hence, political evolution involved the creation of discrete social and symbolic space, in addition to physical ones (Abrutyn and Lawrence 2010): the demarcation of public space and the erection of monuments stratified space "and hence the people who were allowed access to different space, creating and marking centers and peripheries...[which] gave members of new polities a ready-made store of understanding about the meaning of such architecture" (Joyce 2000:72). The same types of processes can be identified in many of the Axial Age cases that fascinated Eisenstadt. In ancient Judah/Israel, for instance, Abrutyn (2015b) draws from archaeological and textual evidence-including Biblical exegesisto demonstrate how religious entrepreneurs leveraged the exile in Babylon (c. 587-536 BCE) to work out

\footnotetext{
${ }^{5}$ It is beyond the scope of this paper, but there is no reason to assume that all actors internalize every center to the same degree. Some actors, individual and/or collective, find themselves further from the center and its resource base and, thereby, are less likely to care about the center, let alone have the relevant role-identity activated. But, the center remains a reality in that it can mobilize agents that impose the role-identity under certain circumstances or, where resistance to playing the role-identity emerges, are authorized to sanction offenders. Where this authority is lacking, the institutional sphere must also be lacking autonomy. Moreover, as societies get larger and more impersonal, stability becomes even more tenuous as alternative models of society are ever-present sources of change and tension.
} 
new symbolic, organizational, and normative frameworks that could be implemented if and when they returned from the exile, rebuilt the second Temple, and imposed their vision of reality on the populace. And while Abrutyn notes that the evolution of Judaism was by no means complete, the freedom the priests and scribes had in the exile was key to creating a discrete religious sphere - that is, they did not have to obey a king or political bureaucracy and were freed from the daily Temple rituals. As one example, Ezekiel (40-48) conceptualized a future Israel in which the temple and the palace were physically and socially demarcated from each other; a radical idea given the typical organization of political and religious space in every society prior.

Thus, sociocultural evolution is the process by which new normative, symbolic, and organizational frameworks supplement or supplant older ones, become crystallized in autonomous institutional spheres, and are both externalized and internalized in the distinct institutional centers that come to be the source of regulation and integration. As new institutional spheres become autonomous and new centers emerge, culture evolves insofar as there are greater numbers of distinct systems structuring day-to-day lives in addition to highly differentiated sets of individuals, roles, collectives, and relationships. Institutional evolution, for Eisenstadt, does not simply unfold as it often appears to do in many functionalist or neo-evolutionary accounts (Chase-Dunn and Hall 1997; Turner 2003). Eisenstadt's second contribution, besides locating the unit of evolution in the institution, is highlighting the nexus between collective agency, exogenous and endogenous exigency, and contingency.

\section{EISENSTADT'S EVOLUTIONISM}

In this section, we first discuss Eisenstadt's concept of institutional entrepreneurs which he developed to provide particular attention to the role of collective action in generating social and cultural transformation. As we elaborate institutional entrepreneurship, we describe the various exigencies and crises which influence the likelihood of emergence, success, and failure. Making explicit Eisenstadt's implicit evolutionary argument, we then demonstrate how he distinguished between exogenously- 
driven evolution (Spencerian) and endogenously-driven evolution (Durkheimian). After differentiating the evolutionary mechanisms, we focus on three major crises that influence entrepreneurship outcomes: trust, power, and meaning. Finally, we focus on Eisenstadt's attention to nuance and historical contingencies by centering our discussion on the influence of extant resource availability, power structures, and internal markets.

\section{Institutional Entrepreneurs}

The abstract. Weber's (1946a, c) great force of historical change centered on charisma, and in particular, the group that is able to (1) borrow charisma from its founding leader and (2) carry and sustain (and develop) the charismatic leader's cultural patterns over indefinite periods of time. That is, survival of the charismatic authority's new vision the closest equivalent to biological "fitness" at the macro-level. Entrepreneurs are the "switchmen" of history, capable of reorienting people to a new worldview and, therefore, reshaping what people believed are their material and ideal interests and the appropriate means to achieving these interests. Eisenstadt argues that the group is more important than the leader for two reasons. He states, the "first meeting point between charismatic predisposition toward the destruction of institutions [i.e., change] and the exigencies of orderly social organization [i.e., routinization] is demonstrated" in the dilemma of "succession of its [charismatic group's] leadership and the continuity of its organization" (Eisenstadt in Weber 1968:xv). Second, and because of this dilemma,

the test of any great charismatic leader lies not in his [sic] ability to create a single event or great movement, but also in his [sic] ability to leave a continuous impact on an institutional structure - to transform any given institutional setting by infusing into it some of his [sic] charismatic vision, by investing regular orderly offices, or aspects of social organization, with some of his [sic] charismatic qualities and aura (ibid. XV-l, emphasis added).

By utilizing Weber for inspiration, Eisenstadt is able to give his theory a sense of agency. All too often, Lamarckian evolution is dismissed or ignored when theorizing about some types of sociocultural evolution, despite Darwin's (1871 [1994]: see chapter 5 in particular) own belief that natural selection 
was not the sole form of selection at the cultural level. In this vein, Boyd and Richerson (1992) caution against ignoring the power of "guided, nonrandom" variation in which the spread of new means and/or ends is not purely one of diffusion (cf. Henrich 2001). Eisenstadt suggests evolution can be generated by entrepreneurs creating new symbolic, normative, and organizational frames, imposing them through mechanisms of integration and regulation, and qualitatively transforming the meaning of society, of identity, and thereby of reality. ${ }^{6}$

Importantly, Eisenstadt's use of Weber provides one further advantage: contingency. As Colomy (1998) has argued, entrepreneurship is never a linear project of change-nor does it take place in a static environment. Nascent entrepreneurs face resistant elites to whom they must manipulate, appease, accommodate, or defeat. As entrepreneurs strategize, formulate, and deploy projects in order to replace existing elites or to carve new institutional space, it is always a possibility that these projects will remain incomplete and partially enacted (Abrutyn 2009). ${ }^{7}$ Incomplete projects create new vulnerabilities and conditions which may generate new emergent problems (Turner 2010). In rare cases, these projects may be co-opted and completed by existing elites (Abrutyn and Van Ness 2015), thereby making an effort towards autonomy all the more difficult. As entrepreneurs focus on enacting their projects, they must also be cognizant of internal maintenance of the collective. This tenuous balance between navigating extant conditions, the potential for incomplete or co-opted institutional projects, and the need to manage the collective reflects some of the many contingencies that Eisenstadt was keen to integrate into his historical analyses.

The empirical. While Eisenstadt often made sweeping historical generalizations, he expressed considerable clarity in his analysis of religio-cultural entrepreneurship during the Axial Age. For instance, he argued that one of the key forces of religious evolution was the emergence of competing

\footnotetext{
${ }^{6}$ To be sure, not all sociocultural evolution is a product of this, but some cases fit this model (Berman 1983; Wilson 2002; Abrutyn 2015a).

${ }^{7}$ For a more complete discussion on institutional projects see Abrutyn and Van Ness (2015).
} 
entrepreneurs at the margins of civilizations $(1982,1984)$. In some cases, like the Israelites, these actors were on the physical margins of sprawling imperial states like Assyria, Babylon, and Egypt, while in other cases such as the various ascetic movements in ancient India, the margins were far less sweeping and, in many ways, were cognitive-cultural more than geographic (Humphreys 1975). At the edges, the temporary freedom Colomy (1998) asserts is essential to both inventing new frames and articulating them in ways that allow them to be selected through diffusion across communities or elevation by extant elites. In an earlier example, the ancient Israelite entrepreneurs were briefly discussed in this regards. Abrutyn (2015b) highlights three key historical moments in which entrepreneurs were given a degree of freedom and maximized the structural opportunities.

First, when Israel was destroyed by Assyria (722-1 BCE), a contingent of northern actors, high in human capital relative to existing southern counterparts, fled to the southern kingdom of Judah. Judah, a political backwater at the time, was suddenly flung into the political and economic orbit of Assyria, while also being forced to absorb a massive influx of refugees from the north; enough to triple the population (Finkelstein 2013). With political, economic, and cultural exigencies pressing against the small polity, King Hezekiah appears to have exploited the skills of some of the northern priests and/or scribes, which, in turn, allowed these actors the freedom to graft northern religious and cultural ideas onto existing southern ones (Smith-Christopher 2002). Second, a generation later, these actors had fallen out of privileged position when Hezekiah's son Manasseh rolled back his father's reforms and returned to older political and religious patterns; when he would die, the religio-cultural entrepreneurs who had gained the support of a growing upper-middle class killed Manasseh's son and placed a nine year old boy (Josiah) on the throne (Smith 1971 [1987]). When he turned 18, the high priest "found" a "lost" scroll (generally assumed to be the core of Deuteronomy, chaps. 12-26) containing a set of laws given to Moses in Exodus. As many scholars have remarked, the scroll was likely invented during Josiah's earliest days, but was treated by priest, prophet, and scribe alike as authentic (Blenkinsopp 1995; Dever 
2001). Third, when Judah, Jerusalem, and the Temple were destroyed by Nebuchadnezzar and the elite exiled to Babylon (c. 587/6-536), priests and scribes carried many of the traditions with them and were given a high degree of religious autonomy (Pearce 2006), under which they appear to have worked out key aspects of a future Israelite society with a religious sphere distinct from the polity and kinship (Abrutyn 2015b). All three examples show both the importance of continuities and discontinuities in understanding institutional evolution. The initial project was primarily a political one based on political expediency. The latter two projects were religious in nature, but the second remained political too as Jerusalem and the office of the king remained a material reality. Furthermore, all three cases show how entrepreneurship is both constrained and facilitated by external factors such as other elites and entrepreneurs (and their sometimes conflicting, sometimes complementary interests), as well as internal factors such as extant traditions that cannot be ignored or erased.

\section{Selection Processes}

The abstract. While there are different levels of selection and types of selection processes, entrepreneurs are subject to two eponymous selection processes: Spencerian and Durkheimian (Turner and Maryanski 2008; Turner 2012). Spencer's model was rooted in a sort of Lamarckian evolution, which saw structural and cultural innovation as the logical outcome where existing solutions were unable to handle old or new exigencies. That is, when existing solutions fail, actors are likely to act creatively in ways that attempt to ease whatever problems they perceive. Thus, the types of entrepreneurs discussed above are the products of Spencerian selection. These entrepreneurs can be differentiated between endogenous and marginal types. The former-or those Eisenstadt (1964) labeled secondary entrepreneurs - are authorized by existing elites who are purposively trying to resolve real or imagined problems in order to, at least, sustain the status quo, whereas the latter are problematizing the existing social order and proposing to reconstitute it for various reasons (Abrutyn 2014b). In both cases, it is the failure of structure or culture to adequately resolve integrative, regulative, or legitimative pressures. In 
some cases, latent crises already exist and are suddenly recognized or made salient in light of the pressures and/or efforts of the entrepreneur trying to seize the opportunity. Additionally, entrepreneurs can intentionally create the conditions that will amount to a problem requiring innovation (Abrutyn and Van Ness 2015). These conditions may be real or simply perceived. For instance, they may make efforts to convince people that there is some crisis already present needing resolution - even if this crisis is not objectively real - and that their resolution is the best remedy.

For Eisenstadt, then, adaptation and selection occur on the group-level, while evolution is multilevel. On the one hand, entrepreneurs alter their projects to accommodate reactions by other strata, especially elites, as well as assimilate elements of competitor's projects. On the other hand, evolution is most transformative when entrepreneurs succeed in reconfiguring particular institutional centers by carving out physical, temporal, social, and symbolic space for their projects, interests, and resource flows (Abrutyn 2014b). Thus, evolution proceeds on the group and institutional level. Meso-level institutional entrepreneurs are the architects of macro-level spheres of social action, exchange, and communication.

Conversely, Durkheimian evolution is that which occurs within the confines of an already autonomous sphere, and, like Darwinian evolution, is driven by competition between social units over scarce institutional resources (cf. Aldrich and Ruef 2006). Rueschemeyer (1977) has noted, for instance, that newly differentiated social units often set goals incommensurate with the center. In addition, as population ecology research shows, organizations compete within fields or niches all the time for limited resources. In some cases, the outcome leads to new niches and gradual growth occurs, whereas in other cases aspiring entrepreneurs may emerge within a niche and attempt to transform the niche into its own autonomous institutional sphere; both of which are found in Chaves' (2004) work on congregational niches. Additionally, Eisenstadt's (1982, 1984, 2012) work on heterodoxies would fit into Durkheimian selection, as competition within a pre-existing institutional framework was a dynamic 
historical force in many cases such as the Indian and Israelite Axial Age, as well as the gestation of Christianity in the face of Gnostic and other competitors.

Thus far, the basic tension of entrepreneurial projects has been alluded to throughout. In essence, successful entrepreneurs must find a way to balance self-interest with collective-oriented goals. It is not enough to "pretend" to have a larger proportion of the population's interests at heart; eventually, this façade will be the entrepreneur's undoing. Conversely, totalistic collective-orientations fail too because entrepreneurs are loathe to monopolize the resources necessary to carve the physical, temporal, social, and symbolic space to serve their interests. Thus, balancing the collective-oriented side and the self-interested side becomes a tenuous balance. The decisions elites make at one point may come back to haunt them later, or may force them to swing the other direction quite rapidly. Likewise, successful entrepreneurship can bring about immediate or prolonged cultural and structural shifts. These changes might create holes or opportunities by which future entrepreneurs can capitalize; thus entrepreneurs must continually assess their "fit" in the environment to not only preserve their position but also to defend against vulnerabilities (Rueschemeyer 1977). Therefore, until entrepreneurs are able to institutionalize their cultural assemblage, they are inherently unstable as the needs of the group and the needs of the followers and potential recruits sit on a razor thin precipice.

The empirical. Examples of selection pressures abound. Christopher Chase-Dunn and colleagues (Chase-Dunn and Hall 1997; Chase-Dunn et al. 2008) has shown the earliest city-states faced population pressures related to natural growth, state planning, and immigration/emigration. His "iteration" model includes various other forces such as resource scarcity, ecological degradation, and internal or external conflicts that result from population pressures as well as intensify them. As pressures ramp up, so to speak, a threshold is reached (Abrutyn and Lawrence 2010) under which these societies (and even societies today) face crossroads: evolve politically, or risk external conquest from better organized groups or collapse (Yoffee and Cowgill 1988). Archaeological and textual evidence clearly shows both 
the successful and unsuccessful methods political entrepreneurs employed under these pressures, including the generalization of culture to better integrate increasingly disparate populations (e.g., religious pantheons), improvement in transportation and communication technologies to regulate and coordinate social units, and the use of redistributive economic mechanisms to create a degree of dependency on the state and its services (Adams 1966). To be sure, creating a standing army and improving military technologies further facilitated the evolution of human societies and political autonomy (Carneiro 1978), but only as handmaiden to the other innovations as coercion is always unstable over the long-run.

A second example can be drawn from the evolution of an autonomous legal sphere in its earliest stages. In the $11^{\text {th }}$ century $C E$, a set of entrepreneurs in the Catholic Church coalesced around a plan to carve out a truly discrete religious sphere like none before it (Berman 1983; Abrutyn 2009). The Church, prior to the Gregorian Reformation-led by the eponymous Pope Gregory VII (1073-1085), was severely delimited by the decentralized nature of European chief- and kingdoms (Southern 1970). Seizing the opportunity, religious entrepreneurs actively sought to "create" a distinct religious sphere vis-à-vis the European polities and local, tribal kin systems (Jellenbach 1945). On the one hand, the Pope declared himself separate from the Holy Roman Emperor (Henry IV) and all other kings, positing that the Bishops serving each king could only be elected by the Church. This was a radical departure from tradition in so far as the king had the sole authority to select who was the Church representative in his court. On the other hand, the Church sought to extend its influence to its local parishes, which included making priests celibate (and, thus, expropriating the priest's claims to land and property) (Goody 1984), subsuming local gods into the Catholic tradition by way of sainthood (Sharot 2001), and making marriage a sacrament and, therefore, of principal concern to the Church (Gies and Gies 1986). Driving these changes was the authorization of a new set of entrepreneurs: legal scholars, exemplified by Gratian (1582 [1993]), who invented both the techniques associated with modern legal argumentation and 
research as well as began the process of professionalizing a body of legal scholars devoted to law and conflict resolution/justice. In the process of religious entrepreneurship, a whole host of selection pressures conspired to generate the type of environment conducive to legal entrepreneurship and legal autonomy (Abrutyn 2009).

For one thing, conflict intensified between the political and religious spheres, culminating in Henry IV's famous Walk of Canossa. When armed conflict failed, and the two spheres were formally accepted as discrete by both sets of elites, there were pressures for other ways to resolve conflicts. Quite rapidly, legal entrepreneurs filled the void, taking their training in Canon law to invent Royal, Manorial, Urban, and then Mercantile law (Berman 1983). They became indispensable "weapons" in struggles between courts, between court and Church, between merchants and royal actors, and between gradually growing autonomous cities and the old gentry (Weber 1927 [2002]). As the internal complexity of legal knowledge grew, universities popped up in Paris, Bologna, and Salerno to not only fill the demand for lawyers but also to handle the pressure for organizing legal knowledge (Rashdall 1936). In short, a set of unpredictable exigencies created the opportunities for legal evolution, and legal entrepreneurs took the reins and ran. To be sure, legal autonomy fluctuates across time and space. In the U.S., for example, the Supreme Court as one barometer of legal autonomy cycles from staunchly independent to politically motivated as demonstrated by Madison v. Marbury establishing judicial review, the Dred Scott case and the Taney court that was in the southern state's political pocket, and the Warren court which sided more often against the state's interests (Irons 1999). There is never a time of complete independence, but law is clearly a distinct sphere in the U.S.

\section{Crises as Contingency}

Eisenstadt saw crises as the underlying engine driving entrepreneurship and, thereby, making sociocultural evolution a possibility. This is perhaps not surprising, as many macro-level evolutionary theories posit-using many different metaphors - that crises are engines of evolutionary processes; 
what differs, however, is that Eisenstadt's crises are sociocultural-meaning, they are endogenous to a society or larger civilizational unit. Hence, we can tentatively classify a typology: environmentalecological crises like droughts, famines, or disease (Diamond 2004); demographic-material crises wrought by population pressures or inter- or intra-societal conflict (Turner 2003); and, finally, the sociocultural crises identified by Eisenstadt and revolving around integration (Abrutyn and Turner 2011), regulation (Turner 2010), or meaning (Abrutyn 2014b). To be sure, his cultural crises may result from external or internal material causes which shape the texture and direction of innovation, yet entrepreneurs experience and frame their projects in the language of cultural dilemmas. In analyzing the Axial Age, for instance, Eisenstadt (2012:285) remarked that "charismatic tendencies are more likely to arise in periods of social turmoil or disintegration," but the solutions were found in religio-cultural innovation. Thus, while the "natural" crises produce Darwinian types of selection and the second type seems related to "ultimate" causes, the sociocultural crises are the fuel that drives institutional evolution. Organizational, symbolic, and normative innovation are, in essence, inventions meant not to reduce population pressures, but to impose a just, efficient, and moral order on a social environment perceived as lacking or losing order.

In short, crises are akin to the selection pressures many contemporary neo-evolutionists speak of as driving innovation and decision-making (Turner 2010, 2012). Crises, by no means, have readily available solutions, nor should we expect that all crises will be perceived or resolved efficaciously when perceived in the short- or long-run. Rather, for Eisenstadt, crises placed pressure on actors to mobilize and organize charisma to make sense of and resolve whatever the entrepreneurs came to believe was the underlying problem. Because there is a phenomenological component to crisis, there is no reason to believe that some cases of sociocultural evolution weren't due to "radical" entrepreneurs creating a crisis, or sense of crisis, by capitalizing on free-flowing resources and using them in a way to mount a significant challenge to the status quo. Whether objectively real, or subjectively felt, Eisenstadt 
highlights three crises that may be able to create, magnify, or frame qualitative transformation: trust, power, and meaning.

Trust. Durkheim's work was centered on the production of trust and commitment, and ultimately, solidarity. Though he initially looked for the causes and consequences of trust in social structure-e.g., in human mutual interdependence and the division of labor-he would reject this idea later in his career and turn towards the social psychological dynamics associated with interaction rituals and emotion. More generally, what Durkheim revealed was the tenuous balance in any relationship, group, network, or larger social unit-like a community, institution, or society-between individual goals and desires and the group's goals and need for cooperation, self-sacrifice, and altruistic behavior. Experimental social psychology (Lawler et al. 2009) and interaction rituals theory (Collins 2004) have confirmed Durkheim's suspicions that trust is inseparable from the symbolic dimensions of social life, especially in relationship to generating, reproducing, and sustaining affect.

At the macro-level, the problem of trust becomes especially salient and challenging as larger groups are inherently stratified vertically (hierarchically) and horizontally (functionally), which puts pressure on elites to prevent conflict, regulate competition, and encourage appropriate interaction, exchange, and communication (Abrutyn 2014b). Crises of trust are often rooted in real or perceived deviance on the part of certain actors. We often assume, for instance, that members of a group will take certain dispositions and orientations and not act (overly) self-interestedly; when they do, they potentially tear the normative fabric, problematize collective interests in maintaining social order, and, in effect, call into question their own dedication to the center. Crises emerge where heterogeneity grows untenable, conflict resolution is inefficacious, and basic guidelines for interacting are lacking. As such, trust is often generated through normative mechanisms like generalized symbolic media which standardize interaction patterns, exchange rules, and communication and, thereby, pre-contractually 
induce basic levels of trust between strangers (Abrutyn and Turner 2011; Luhmann 2012; Abrutyn 2015c).

Power. Integrative mechanisms are also mechanisms of social control intended to regulate interaction, exchange, and communication; therefore, they are also sources of power. Power becomes problematic because there are (1) four bases of power-coercive/military, political/administrative, economic, and ideological/symbolic (Mann 1986), (2) centralization within any one network of power engenders winners and losers, and domination and natural opposition, and (3) attempts to consolidate multiple networks runs against the interests of within-network centralization (Turner 1995). Thus, while centralization and consolidation of power appear to be necessary conditions for societal growth and complexity, there are tensions inherent in power dynamics between superordinates-subordinates and elites across networks (Tilly 1990). Indeed, Boehm (1999) claims the relationship between power and human nature to be the ultimate antagonism: on the one hand, humans work hard to resist authority and hierarchy while, on the other hand, hierarchies naturally form as population size and density increase and emerging problems demand coordination. Hence, crises rooted in regulation and power emerge when either (a) power is too consolidated and/or centralized and the appropriation of resources in the center is so imbalanced that the margins grow weak and people no longer commit to the center; (b) power differentials are exposed or defined by marginal actors as inefficacious, unjust, and immoral; or (c) factions within the elite, or between elites and newly minted rivals or competitors, draw resources and attention away from governing and refocus it on costly struggles over power.

To elaborate, when the over-consolidation of resources and power is perceived, peripheral entrepreneurs are likely to radically innovate in an attempt to overthrow the center as they feel completely "shut out" from traditional channels of access. When elite cleavages emerge within the center, new alliances might develop between elites and nascent entrepreneurs (Tarrow 1998). These entrepreneurs may come from the periphery-wherein these new coalitions funnel resources for radical 
innovation-or through more centrally embedded, reform-oriented entrepreneurs. This is to say, real or perceived crises in power provide the conditions for the potential emergence of entrepreneurs.

Meaning. Finally, crises emerge around the production of a sense of shared meaning. Though materialists often reject the need humans have for meaning, clearly ontological security and the search for a relatively coherent cosmology cannot be ignored, lest anomic terror, as Berger (1969) labels it, spread through the community and destroy the morale and energy of the group. Cultural generalization, of course, contributes greatly to preventing anomie (Parsons and Bales 1955:359-63). By producing generalized symbolic mechanisms of integration, like specialized media, a perception of consensus can be erected (Abrutyn 2015c). Also, the formalization of rules, authority, and accepted social practices in the form of institutional logics simplify a complex, differentiated reality as traditional and legal-rational authority look to encode meaning in the taken-for-grantedness of routine, whether it rests on nearlyhabitual action, or rule-governed, sphere-delimiting formal codes of conduct (Thornton et al. 2012). Leadership, charisma, and power, for example, become routinized, symbolic, external representations of the group (Weber 1968). But, entrepreneurs must also impose their vision of reality on others through ceremonial and mundane rituals that consciously and unconsciously indicate to the performer(s) and the observer(s) acceptance of a set of rules and beliefs about what is good, right, and moral (Goffman 1967; Alexander 2004). Crises in meaning can emerge where extant meaning structures fail to continuously make sense of external reality and, in turn, fail to prevent ontological insecurities (Giddens 1984); where counter-ideological frames label existing power structures as unjust and immoral (Almond et al. 2003); or where factions appear within the power-elite that threaten to pull back the proverbial "curtain" and threaten trust (Skocpol 1977). When trust breaks down, previously taken-for-granted meanings are called into question-therein providing the conditions for alternative world visions.

\section{Sociocultural Contingency}

Entrepreneurship, for Eisenstadt, is the ultimate contingency in history. Entrepreneurs are not 
inevitable characters in the drama of social change, but rather potential energy waiting to be unleashed when historical and sociocultural conditions intersect with what may best be termed structural holes (Burt 2004) or opportunities (McAdam [1982] 1999). That being said, entrepreneurs are not entirely passive but can facilitate the conditions providing the potential for success. Eisenstadt argued that three conditions were central forces that governed the success entrepreneurs might expect and, more importantly, whether evolutionary processes will even emerge-after all, selection is not a constant because variation, for numerous reasons, is not always salient. ${ }^{8}$

Resource availability. More than anything, entrepreneurs need resources to sustain organization, realize goals, and expand. Eisenstadt recognized the tremendous limitations resources put on entrepreneurs. For example, there may simply be a shortage of human and/or material resources. Political entrepreneurship becomes excessively difficult where a surplus of material goods cannot be marshaled, while the religious entrepreneurship of the Axial Age could not have occurred earlier where populations were smaller, urban environments fewer, and local cultures more insulated. Further, the flow of resources may be highly restrictive and monopolized by the center, which reduces the likelihood marginal actors will be able to organize and mobilize. Unlike the first dilemma of scarcity, the flow of resources can be reconfigured-though, not without a struggle and risk.

Entrepreneurs are not simply resigned to needing human and material resources. Symbolic resources are equally as important for success. Entrepreneurs need to be able to mobilize and monopolize, for example, coherent cosmologies and ideological frames, insignia and emblems, and "vocabularies of motives" that contribute to communication. Although not strictly symbolic, they need to tap into "charismatic fervor...rooted in the attempt to come into contact with the very essence of being," to establish contact with the sacred, and thus, to pursue projects of ultimate ends (Eisenstadt in Weber 1968:xix). Finally, as the social movement's literature and social psychology have demonstrated,

\footnotetext{
${ }^{8}$ Again, the list of conditions is not exhaustive, nor meant to be. It is Eisenstadt's theory we are interested in, not a general theory of evolution.
} 
they must mobilize emotional resources. These mobilized emotional resources charge symbols that allow sustained fervor and commitment to the group (Collins 2004). In any given society, emotions become stratified resources and, thereby, pursued and hoarded. Entrepreneurs can nurture intramovement emotional climates in distinct ways which might become alluring for new recruits and followers (Jasper 1997), or provide the resources necessary to preserve through failure (Summers-Effler 2009; Summers-Effler and Kwak 2015). Other adherents may experience righteous indignation or experience morality in bringing the entrepreneur's vision to fruition. The cultivated emotional climate may foster stronger commitment within the group as it deepens trust between members (Lawler et al. 2009), while also extending the possibility of attributing blame to an external target for the experience of negative emotions (Mackie et al. 2009). Furthermore, particularly strong emotional climates generated by otherwise-sidelined groups may generate "fringe effects," whereby energized emotional reactions to crises in the public sphere serve as magnets through which groups embed their cultural messages in public discussions and collective memories (Bail 2012).

Extant power structures. Most evolutionary theories identify existing power arrangements as crucial to opportunity structures (Turner 2010). Where power is highly consolidated and centralized into a few hands, threats - whether real or perceived-posed by entrepreneurs can be dealt with swiftly and with few repercussions. The consolidation of power and resources also presents potential entrepreneurs with a measuring stick indicating just how much resources they will need to mobilize efficaciously and achieve their goals. Of course, a dialectical process always threatens sharply distinguished power structures, rendering a sense of impenetrability moot. That is, as the ambitions and needs of elites grow, they naturally generate greater complexity that requires new internal order to resolve (Rueschemeyer 1977). For instance, the formation of new or more ambitious goals puts pressure on leaders to create more bureaucracy to more efficiently handle the organization and realization of these goals. Balancing power and efficiency often leads to irrationalities in the structure, as newly differentiated political units 
may become corrupt, pursue goals incommensurate with the center, or develop their own goals that run counter to the efforts of political elites. For these reasons, Eisenstadt recognized secondary elites-or the subsidiary collectives that are either authorized by the primary elites to handle new problems or who grow increasingly indispensable to the primary elites-as potential pools of nascent entrepreneurship. Put differently, these secondary elites could become the evolutionary force working to alter the existing institutional sphere or, more radically, to carve out a new institutional sphere to protect and realize their interests vis-à-vis the elites that created them (Jenkins and Perrow 1977).

Internal markets. Finally, Eisenstadt felt that the number, size, and level of differentiation among intra-societal markets played a major role in entrepreneurship. On the one hand, an economic stratum with some wealth has always been influential for entrepreneurial efforts, as they become a potential base of material support. On the other hand, markets facilitate the flow of resources and information, which means that more markets create more dynamism and weaken centralized control (Collins 1990). Economic or non-economic markets encourage intense, frequent, and accelerated social exchanges. Ideas spread faster; innovations diffuse quicker; movements form rapidly; and counterideologies take hold more readily. Markets are dynamic forces, and as Collins shows, can be layered on top of each other to form meta-markets that penetrate everyday reality even more.

Not surprisingly, Eisenstadt (1971) saw institutional spheres, in part, as generalized markets of exchange: that is, institutional spheres allow for new media of exchange and communication to emerge and reorient the emotions, attitudes, and actions of a greater proportion of the population; generate and sustain a generalized set of means-ends relationships, decision-making processes, themes of discourse, and value-orientations; and, ultimately, give entrepreneurs the opportunity to monopolize the production and distribution of media, like money and/or sacredness (Abrutyn 2015c). Moreover, these markets open the possibility for creating demand, as the greater are the number of markets, the greater is the familiarity and comfortability the general population has with generalized symbolic media. 


\section{CONCLUSION}

Arguably, Eisenstadt's most well-known contributions primarily come from his research on "multiple modernities." This work has influenced research in both cultural sociology and comparative historical sociology. Less appreciated has been his evolutionary theory of social and cultural change. In this article, we revisited Eisenstadt's evolutionary theory in order to make explicit his potential contributions to the neo-evolutionary tradition to most clearly demonstrate where his contribution could be further appreciated. In order to facilitate this integration, we synthesized Eisenstadt's evolutionary work and translated his terminology with more recent neo-evolutionary developments; this translation, we believe, will help contemporary scholars hone in on potential contributions within current debates. Additionally, we dimensionalized many of his insights while supplementing his abstract contributions with concrete, empirical historical case studies.

In particular, most social scientists, biologists, and psychologists interested in sociocultural evolution have remained ardently committed to a Darwinian, natural selection framework despite Darwin's own reticence about the ubiquity of natural selection on the individual level in societies (for a critique, see Turner 2012). Those that do advocate for other forms of selection often take for granted the role actual actors and historical/sociocultural contingencies play in evolution. Eisenstadt, in his effort to move beyond the unfolding cultural evolution of Parsons and Bellah, went back to Weber and highlighted the affects entrepreneurs had on qualitative transformation. By leveraging his meso-level model, we focused on his unit of analysis whereby evolution happens: institutional spheres. After articulating where he saw evolution take place, we made explicit where he saw evolutionary processes select upon. By integrating Weber's work on charismatic carrier groups with Durkheim's ecologicalevolutionism, he developed his concept of institutional entrepreneurs. This integration provided a more dynamic model of sociocultural evolution grounded in empirical historical cases with a particular attention to historical contingencies, structural and cultural conditions, and the potential for innovation. 
Importantly, by focusing on selection processes at the meso-level, he re-centered purposeful agents as the engine of social and cultural change. We provided both a theoretical understanding by focusing on the more abstract while also providing empirical examples with references to more concrete case studies, such as in our explanation of religio-cultural entrepreneurs during the Axial Age. Without losing historical nuance, Eisenstadt integrated into his work an attention to crises of trust, power, and meaning, as well as the constraints and opportunities inherit in resource availabilities, existing power structures, and internal markets.

Though beyond the scope of this paper, we believe there are a few specific ways which future research can benefit from this renewed focus on Eisenstadt's neo-evolutionary contribution. Most notable is the potential contribution to social movement and collective behavior research. Social movement research has a tendency to privilege political change, with less of a focus on social and cultural change in other spheres of social life (for similar critiques see Jasper 1997; Snow 2004). Eisenstadt's theory of institutional entrepreneurs affords researchers an opportunity to make sense of agentic change in other spheres beyond the polity, such as religion and economy. ${ }^{9}$ His work also allows for interesting comparisons between collectives mobilizing from different structural positions. With advances in communication technologies, peripheral entrepreneurs are afforded greater potential for comparatively autonomous mobilization with an increased ability to appeal to and mobilize dormant resource bases (see Earl and Kimport 2011; Castells 2012). Additionally, new technology affords entrepreneurs greater accessibility to institutional projects in disparate domains which provides an increased opportunity to emulate and creatively combine mobilization strategies in new contexts (see Abrutyn and Van Ness 2015).

\footnotetext{
${ }^{9}$ This is not to say social and cultural change in other spheres has been completely unstudied, however. For some examples of mobilization in the economic sphere see: King and Pearce (2010), King and Soule (2007), Soule (2009) and for religious change see: Zald and McCarthy (1987), Chaves (1997), Wilde (2007).
} 
Additionally, because his empirical cases were rooted in historical data, Eisenstadt's

contribution can be extended by future research through the integration of microsociological approaches to social and cultural change. In this respect, social movement research can extend his theory by choosing a social movement organization working towards institutional change, form testable hypotheses for organizational project success or failure, and therefore account for particular movement outcomes in a systematic fashion by juxtaposing observed events with expected events according to the insights explicated above. Furthermore, Eisenstadt's meso-level theory can be supplemented by microlevel research from new social movements (e.g., Melucci 1985; Gamson 1989) and the cultural turn (e.g., Jasper 1997; Polletta 1998) in order to explicate how identities and cultural meanings are mobilized and contested on the ground. This approach should also critique or extend Eisenstadt's research in relation to gender, class, and race - issues which Eisenstadt was not particularly attentive to in his work. In this regard, historical and ethnographic research from the second wave of feminism, civil rights, student movements, and other recent research may add these important dimensions. All said, we believe there is much to appreciate in Eisenstadt's theory of sociocultural evolution and see great value for future research.

\section{REFERENCES}

Abrutyn, Seth. 2009. "Toward a General Theory of Institutional Autonomy." Sociological Theory 27(4):449-65.

-. 2013a. "Political Evolution, Entrepreneurship, and Autonomy: Causes and Consequences of an "Axial" Moment." Research in Political Sociology 21:3-29.

-. 2013b. "Reconceptualizing Religious Evolution: Toward a General Theory of Macro-Institutional Change." Social Evolution and History 12(2):5-36.

-. 2013c. "Revisiting and Reinvigorating Evolutionary Institutionalism: Bringing Institutions Back to Life." Current Perspectives in Social Theory 31:247-76.

-. 2014a. "Religious Autonomy and Religious Entrepreneurship: An Evolutionary-Institutionalist's Take on the Axial Age." Comparative Sociology 13(2):105-34. 
-. 2014b. Revisiting Institutionalism in Sociology: Putting the "Institution" Back in Institutional Analysis. New York: Routledge.

-. 2015a. "The Institutional Evolution of Religion: Innovation and Entrepreneurship in Ancient Israel." Religion 45(4):505-31.

-. 2015b. "Pollution-Purification Rituals, Collective Memory, and the Evolution of Religion: How Cultural Trauma Shaped Ancient Israel." American Journal of Cultural Sociology 3(1):123-55.

-. 2015c. "Money, Love, and Sacredness: Generalized Symbolic Media and the Production of Instrumental, Affectual, and Moral Reality." Czech Sociological Review 51(3):445-71.

Abrutyn, Seth, and Kirk Lawrence. 2010. "From Chiefdoms to States: Toward an Integrative Theory of the Evolution of Polity." Sociological Perspectives 53(3):419-42.

Abrutyn, Seth, and Jonathan H. Turner. 2011. "The Old Institutionalism Meets the New Institutionalism." Sociological Perspectives 54(3):283-306.

Abrutyn, Seth, and Justin Van Ness. 2015. "The Role of Agency in Sociocultural Evolution: Institutional Entrepreneurship as a Force of Structural and Cultural Transformation." Thesis Eleven 127(1):5277.

Adams, Robert McC. 1966. The Evolution of Urban Society: Early Mesopotamia and PreHispanic Mexico. Chicago: Aldine Publishing Company.

Aldrich, Howard, and Martin Ruef. 2006. Organizations Evolving. London: Sage.

Alexander, Jeffrey C. 1992. "The Fragility of Progress: An Interpretation of the Turn Toward Meaning in Eisenstadt's Later Work." Acta Sociologica 35(2):85-94.

-. 2004. "Cultural Pragmatics: Social Performance between Ritual and Strategy." Sociological Theory 22(4):527-73.

Alexander, Jeffrey C., and Paul Colomy (Eds.). 1990. Differentiation Theory and Social Change: Comparative and Historical Perspectives. New York: Columbia University Press.

Almond, Gabriel A., R. Scott Appleby, and Emmanuel Sivan. 2003. Strong Religion: The Rise of Fundamentalism Around the World. Chicago: University of Chicago Press.

Bail, Christopher A. 2012. "The Fringe Effect: Civil Society Organizations and the Evolution of Media Discourse about Islam since the September 11th Attacks." American Sociological Review 77(7):855-79.

Bellah, Robert N. 1964. "Religious Evolution." American Sociological Review 29(3):358-74.

Benford, Robert D., and David A. Snow. 2000. "Framing Processes and Social Movements: An Overview and Assessment." Annual Review of Sociology 26(1):611-39.

Berger, Peter. 1969. The Sacred Canopy: Elements of a Sociological Theory of Religion. New York: Anchor Books.

Berman, Harold J. 1983. Law and Revolution: The Formation of the Western Legal Tradition. Cambridge, MA: Harvard University Press.

Blenkinsopp, Joseph. 1995. Sage, Priest, Prophet: Religious and Intellectual Leadership in Ancient Israel. Louisville, KY: Westminster John Knox Press.

Blute, Marion. 2010. Darwinian Sociocultural Evolution: Solutions to Dilemmas in Cultural and Social Theory. Cambridge: Cambridge University Press.

Boehm, Christopher. 1999. Hierarchy in the Forest: The Evolution of Egalitarian Behavior. Cambridge: Harvard University Press.

Boyd, Robert, and Peter Richerson. 1992. "How Microevolutionary Processes Give Rise to History." Pp. 179-208 in History and Evolution, edited by M.H. Nitecki and D.V. Nitecki. Albany: State University of New York Press.

Burt, Ronald S. 2004. "Structural Holes and Good Ideas." American Journal of Sociology 110(2):349-99. 
Carneiro, Robert L. 1978. "Political Expansion as an Expression of the Principle of Competitive Exclusion." Pp. 205-24 in Origins of the State: The Anthropology of Political Evolution, edited by Ronald Cohen and Elman R. Service. Philadelphia: Institute for the Study of Humans Issues.

Castells, Manuel. 2012. Networks of Outrage and Hope: Social Movements in the Internet Age. Polity. Chase-Dunn, Christopher, Alexis Alvarez, Oswin Chan, Ben Fierro, and Hiroko Inoue. 2008. "Upsweep Inventory: Scale Shifts of Settlements and Polities in World-Systems Since the Stone Age." IROWS Working Paper \#39, Available: http://irows.ucr.edu/papers/irows39/irows39.htm.

Chase-Dunn, Christopher, and Thomas D. Hall. 1997. Rise and Demise: Comparing World-Systems. Boulder, CO: Westview Press.

Chaves, Mark. 1997. Ordaining Women: Culture and Conflict in Religious Organizations. Cambridge, MA: Harvard University Press.

-. 2004. Congregations in America. Cambridge: Harvard University Press.

Chirot, Daniel. 1994. How Societies Change. Thousand Oaks, CA: Pine Forge Press.

Collins, Randall. 1990. "Market Dynamics as the Engine of Historical Change." Sociological Theory $8(2): 111-35$.

-. 2004. Interaction Ritual Chains. Princeton: Princeton University Press.

Colomy, Paul. 1998. "Neofunctionalism and Neoinstitutionalism: Human Agency and Interest in Institutional Change." Sociological Forum 13(2):265-300.

Darwin, Charles. [1871] 1994. The Descent of Man. London: Penguin.

Dever, William G. 2001. What Did the Biblical Writers Know \& When Did They Know It? Grand Rapids, MI: William B. Eerdmans.

Diamond, Jared. 2004. Collapse: How Societies Choose to Fail or Succeed. London: Viking Adult.

Earl, Jennifer, and Katrina Kimport. 2011. Digitally Enabled Social Change: Activism in the Internet Age: The MIT Press.

Earle, Timothy. 1991. Chiefdoms: Power, Economy, and Ideology. Cambridge: Cambridge University Press.

Eisenstadt, S.N. 1963. The Political System of Empires: The Rise and Fall of the Historical Bureaucratic Societies. New York: Free Press.

-. 1964. "Social Change, Differentiation and Evolution." American Sociological Review 29(3):375-86.

- (Ed.). 1965. Essays on Comparative Institutions. New York: John Wiley \& Sons.

-. 1971. Social Differentiation and Stratification. Glenview, III: Scott, Foresman and Company.

-. 1977. "Sociological Theory and an Analysis of the Dynamics of Civilizations and of Revolutions." Daedalus 106(4):59-78.

-. 1980. "Cultural Orientations, Institutional Entrepreneurs, and Social Change: Comparative Analysis of Traditional Civilizations." American Journal of Sociology 85(4):840-69.

-. 1982. "The Axial Age: The Emergence of Transcendental Visions and the Rise of Clerics." European Journal of Sociology 23(2):294-314.

-. 1984. "Heterodoxies and Dynamics of Civilizations." American Philosophical Society 128(2):104-13.

- (Ed.). 1986. The Origins and Diversity of Axial Age Civilizations. Albany: State University of New York Press.

-. 1987. "Macrosociology and Sociological Theory: Some New Directions." Contemporary Sociology 16(5):602-9.

-. 1990. "Modes of Structural Differentiations, Elite Structures, and Cultural Visions." Pp. 20-51 in Differentiation Theory and Social Change: Comparative and Historical Perspectives, edited by Jeffrey C. Alexander and Paul Colomy. New York: Columbia University Press.

—. 2000. "Multiple Modernities." Daedalus 129(1):1-29. 
-. 2012. "The Axial Conundrum between Transcendental Visions and Vicissitudes of Their Institutionalizations: Constructive and Destructive Possibilities." Pp. 277-93 in The Axial Age and Its Consequences, edited by R.N. Bellah and H. Joas. Cambridge, MA: Belknap Press.

Eisenstadt, S.N., M. Abitol, and N. Chazan. 1987. "Cultural Premises, Political Structures and Dynamics." International Political Science Review 8(4):291-306.

Finkelstein, Israel. 2013. The Forgotten Kingdom: The Archaeology and History of Northern Israel. Atlanta: The Society of Biblical Literature.

Flannery, Kent V. 1972. "The Cultural Evolution of Civilizations." Annual Review of Ecology and Systematics 3:399-426.

Franks, David D., and Jonathan H. Turner (Eds.). 2013. Handbook of Neurosociology. New York: Springer. Gamson, Josh. 1989. "Silence, Death, and the Invisible Enemy: Aids Activism and Social Movement 'Newness'." Social Problems 36(351-367).

Giddens, Anthony. 1984. The Constitution of Society. Berkeley: University of California Press.

Gies, Frances, and Joseph Gies. 1986. Marriage and the Family in the Middle Ages. New York: Perennial Library.

Goffman, Erving. 1967. Interaction Ritual: Essays on Face-to-Face Behavior. New York: Pantheon Books.

Goody, Jack. 1984. The Development of Family and Marriage in Europe. Cambridge: Cambridge University Press.

Goodwin, Jeff. 2001. No Other Way Out: States and Revolutionary Movements, 1945-1991. New York: Cambridge University Press.

Gratian. 1582 [1993]. The Treatise on Laws with The Ordinary Gloss. Washington D.C.: Catholic University of America Press.

Henrich, Joseph. 2001. "Cultural Transmission and the Diffusion of Innovations: Adoption Dynamics Indicate That Biased Cultural Transmission is the Predominate Force of Behavioral Change." American Anthropologist 103(4):992-1013.

Humphreys, S.C. 1975. "'Transcendence" and Intellectual Roles: The Ancient Greek Case." Daedalus 104(2):91-118.

Irons, Peter. 1999. A People's History of the Supreme Court: The Men and Women Whose Cases and Decisions Have Shaped Our Constitution. New York: Penguin Books.

Jasper, James M. 1997. The Art of Moral Protest. Chicago: The University of Chicago.

Jellenbach, C. 1945. Church, State, and Christian Society at the Time of the Investiture Conflict. Oxford: Oxford University Press.

Jenkins, J. Craig, and Charles Perrow. 1977. "Inusrgency of the Powerless Farm Worker Movements (1946-1972)." American Sociological Review 42:249-68.

Jepperson, Ronald L. 1991. "Institutions, Institutional Effects, and Institutionalism." Pp. 143-63 in The New Institutionalism of Organizational Analysis, edited by Walter W. Powell and Paul J. DiMaggio. Chicago: The University of Chicago Press.

Joas, Hans. 2012. "The Axial Age Debate as Religious Discourse." Pp. 9-29 in The Axial Age and Its Consequences, edited by R.N. Bellah and H. Joas. Cambridge, MA: Belknap Press.

Joyce, Rosemary A. 2000. "High Culture, Mesoamerican Civilization, and the Classic Maya Tradition." Pp. 64-76 in Order, Legitimacy, and Wealth in Ancient States, edited by Janet Richards and Mary Van Buren. Cambridge: Cambridge University Press.

King, Brayden G., and Nicholas A. Pearce. 2010. "The Contentiousness of Markets: Politics, Social Movements, and Institutional Change in Markets." Annual Review of Sociology 36(1):249-67.

King, Brayden G., and Sarah A. Soule. 2007. "Social Movements as Extra-Institutional Entrepreneurs: The Effect of Protests on Stock Price Returns." Administrative Science Quarterly 52:413-42.

Kurzman, Charles. 2004. The Unthinkable Revolution in Iran. Cambridge: Harvard University Press. 
Lawler, Edward J., Shane Thye, and Jeongkoo Yoon. 2009. Social Commitments in a Depersonalized World. New York: Russell Sage.

Lenski, Gerhard. 1966. Power and Privilege: A Theory of Social Stratification. New York: McGraw-Hill. -. 2005. Ecological-Evolutionary Theory. Boulder: Paradigm.

Luhmann, Niklas. 1995. Social Systems. Stanford: Stanford University Press.

-. 2012. Theory of Society. Stanford: Stanford University Press.

Machalek, Richard, and Michael W. Martin. 2016. "Evolutionary Theory." in The Handbook of Contemporary Sociological Theory, edited by Seth Abrutyn. New York: Springer.

Mackie, Diane M., Angela T. Maitner, and Eliot R. Smith. 2009. "Intergroup Emotions Theory." Pp. 285307 in Handbook of Prejudice, Stereotyping, and Discrimination, edited by T.D. Nelson. New York: Psychology Press.

Mann, Michael. 1986. The Sources of Social Power: A History of Power From the Beginning to A.D. 1760. Cambridge: Cambridge University Press.

Maryanski, Alexandra, and Masako Ishii-Kuntz. 1991. "A Cross-Species Application of Bott's Hypothesis on Role Segregation and Social Networks." Sociological Perspectives 34(4):403-25.

Maryanski, Alexandra, and Jonathan H. Turner. 1992. The Social Cage: Human Nature and the Evolution of Society. Stanford: Stanford University Press.

Mayr, Ernst. 2001. What Evolution Is. New York: Basic Books.

McAdam, Doug. [1982] 1999. Political Process and the Development of Black Insurgency, 1930-1970. Chicago, IL: University of Chicago.

McVeigh, Rory, Daniel J. Myers, and David Sikkink. 2004. "Corn, Klansmen, and Coolidge: Structure and Framing in Social Movements." Social Forces 83(2):653-90.

Melucci, Alberto. 1985. "The Symbolic Challenge of Contemporary Movements." Social Research 52:789816.

Meyer, David S., and Debra C. Minkoff. 2004. "Conceptualizing Political Opportunity." Social Forces 82(4):1457-92.

Nolan, Patrick, and Gerhard Lenski. 2010. Human Societies: An Introduction to Macrosociology. Boulder, CO: Paradigm.

Norenzayan, Ara. 2013. Big Gods: How Religion Transformed Cooperation and Conflict. Princeton: Princeton University Press.

Parsons, Talcott. 1966. Societies: Evolutionary and Comparative Perspectives. Englewood Cliffs, NJ: Prentice-Hall.

Parsons, Talcott, and Robert F. Bales. 1955. Family, Socialization and Interaction Process. Glencoe, II: Free Press.

Parsons, Talcott, and Neil J. Smelser. 1956. Economy and Society: A Study in the Integration of Economic and Social Theory. New York: The Free Press.

Pearce, Laurie E. 2006. "New Evidence for Judeans in Babylonia." Pp. 399-411 in Judah and Judeans in the Persian Period, edited by O. Lipschits and M. Oeming. Winona Lake, IN: Eisenbrauns.

Polletta, Francesca. 1998. It Was Like a Fever. Chicago: University of Chicago Press.

Rashdall, Hastings (Ed.). 1936. The Universities of Europe in the Middle Ages: Salerno-Bologna-Paris. Oxford: Oxford University Press.

Richerson, Peter, and Robert Boyd. 2005. Not By Genes Alone: How Culture Transformed Human Evolution. Chicago: The University of Chicago.

Richerson, Peter, and Morten H. Christiansen (Eds.). 2013. Cultural Evolution: Society, Technology, Language, and Religion. Cambridge: MIT Press.

Rueschemeyer, Dietrich. 1977. "Structural Differentiation, Efficiency, and Power." American Journal of Sociology 83(1):1-25. 
Runciman, W.G. 2009. The Theory of Cultural and Social Selection. Cambridge: Cambridge University Press.

Sahlins, Marshall. 1960. "Evolution: General and Specific." Pp. 12-44 in Evolution and Culture, edited by Marshall D. Sahlins and Elman R. Service. Ann Arbor, MI: University of Michigan Press.

Sanderson, Stephen K. 2007. Evolutionism and Its Critics: Deconstructing and Reconstructing an Evolutionary Interpretation of Human Society. Boulder, CO: Paradigm.

Sharot, Stephen. 2001. A Comparative Sociology of World Religions: Virtuosos, Priests, and Popular Religion. New York: New York University Press.

Shils, Edward A. 1975. Center and Periphery: Essays in Macrosociology. Chicago: University of Chicago Press.

Skocpol, Theda. 1977. "State and Revolution: Old Regimes and Revolutionary Crises in France, Russia, and China." Theory and Society 7(1/2):7-95.

Slingerland, Edward, Joseph Henrich, and Ara Norenzayan. 2013. "The Evolution of Prosocial Religions." Pp. 335-48 in Cultural Evolution: Society, Technology, Language, and Religion, edited by P.J. Richerson and M.H. Christiansen. Cambridge: MIT Press.

Smith-Christopher, Daniel L. 2002. A Biblical Theology of Exile. Minneapolis: Fortress Press.

Smith, Eliot R., and Jamie DeCoster. 2000. "Dual-Process Models in Social and Cognitive Psychology: Conceptual Integration and Links to Underlying Memory Systems." Personality and Social Psychology Review 4(2):108-31.

Smith, Morton. 1971 [1987]. Palestinian Parties and Politics that Shaped the Old Testament. London: SCM Press.

Snow, David A., E. Burke Rochford, Steven K. Worden, and Robert D. Benford. 1986. "Frame Alignment Processes, Micromobilization, and Movement Participation." American Sociological Review 51(4):464-81.

Soule, Sarah A. 2009. Contention and Corporate Social Responsibility. New York: Cambridge Univeristy Press.

Southern, R.W. 1970. Western Society and the Church in the Middle Ages. London: Penguin Books.

Summers-Effler, Erika. 2002. "The Micro Potential for Social Change : Emotion, Consciousness, and Social Movement Formation *." Sociological Theory 20(1):41-60.

-. 2009. Laughing Saints and Righteous Heroes. Chicago: University of Chicago Press.

Summers-Effler, Erika, and Hyunjin Deborah Kwak. 2015. "Weber's missing mystics: inner-worldly mystical practices and the micro potential for social change." Theory and Society 44:251-82.

Summers-Effler, Erika, Justin Van Ness, and Christopher Hausmann. 2014. "Peeking in the Black Box: Studying, Theorizing, and Representing the Micro-Foundations of Day-to-Day Interactions." Journal of Contemporary Ethnography.

Tarrow, Sidney. 1998. Power in Movement. Cambridge: Cambridge University Press.

Thornton, Patricia H., William Ocasio, and Michael Lounsbury. 2012. The Institutional Logics Perspective: A New Approach to Culture, Structure, and Process. New York: Oxford University Press.

Tilly, Charles. 1990. Coercion, Capital, and European States, AD 990-1990. Cambridge: Basil Blackwell.

Turner, Jonathan H. 1995. Macrodynamics: Toward a Theory on the Organization of Human Populations. New Brunswick: Rutgers University Press.

-. 2003. Human Institutions: A Theory of Societal Evolution. Lanham: Bowman \& Littlefield Publishers, Inc.

-. 2010. Theoretical Principles of Sociology, Volume 1: Macrodynamics. New York: Springer.

-. 2012. "The Biology and Neurology of Group Processes." Advances in Group Processes 29:1-31.

Turner, Jonathan H., and Alexandra Maryanski. 2008. "The Limitations of Evolutionary Theory From Biology." Sociologica 3:1-22. 
Vaisey, Stephen. 2009. "Motivation and Justification: A Dual Process Model of Culture in Action." American Journal of Sociology 114(+):1675-715.

Verkamp, Bernard J. 1991. "Concerning the Evolution of Religion." The Journal of Religion 71(4):538-57. Weber, Max. 1927 [2002]. General Economic History. New Brunswick: Transaction Publishers.

-. 1946a. "Religious Rejections of the World and Their Directions." Pp. 323-62 in From Max Weber: Essays in Sociology, edited by H. Gerth and C.W. Mills. New York: Oxford University Press.

-. 1946b. "Science as a Vocation." Pp. 129-56 in From Max Weber: Essays in Sociology, edited by H. Gerth and C.W. Mills. New York: Oxford University Press.

-. 1968. Max Weber on Charisma and Institution Building. Chicago: University of Chicago Press.

Wilde, Melissa. 2007. Vatican II: A Sociological Analysis of Religious Change. Princeton, NJ: Princeton University Press.

Wilson, David Sloan. 2001. "Religious Groups as Adaptive Units." History and Philosophy of the Life Sciences 23(3/4):467-503.

-. 2002. Darwin's Cathedral: Evolution, Religion, and the Nature of Society. Chicago: University of Chicago Press.

Wilson, E.O. 1975. Sociobiology: A New Synthesis. Cambridge: Harvard University Press.

Wittrock, Björn. 2005. "The Meaning of the Axial Age." Pp. 51-85 in Axial Civilizations and World History, edited by J.P. Arnason, S.N. Eisenstadt, and B. Wittrock. Leiden: Brill.

Yoffee, Norman. 2005. Myths of the Archaic State: Evolution of the Earliest Cities, States, and Civilizations. Cambridge: Cambridge University Press.

Yoffee, Norman, and George L. Cowgill. 1988. The Collapse of Ancient States and Civilizations. Tucson: University of Arizona Press.

Zald, Mayer N., and John D. McCarthy. 1987. "Religious Groups as Crucibles of Social Movements." in Social Movmeents in an Organizational Society, edited by Mayer N. Zald and John D. McCarthy. New Brunswich, NJ: Transaction. 